\title{
Waste management in terms of material and management
}

\author{
Dr. Mujbil .R Mergan \\ University of Babylon - Iraq
}

\begin{abstract}
Currently, when discussing the issue of environment and disposal of wastes, we highly should consider the effective role and responsibilities of all types of citizen classes in this regard, for such issue is not existed and not considerably considered yet in Iraq, in addition of the absence of waste recycling projects.
\end{abstract}

Key words: - Wastes, products, treatment, recycle, disposal. Management of wastes and their anticipated impact

To establish such an idea, many scientific systems are available today for this purpose, which can assist to meet the technical and economical requirements. This idea can be applied at all companies and factories by establishing a modern and integral industrial system in Iraq to improve living standard and benefit from waste in producing useful products. To practically benefit from useful wastes and turn them to useful uses as well as preventing environment pollution we should develop practical studies to layout optimal methods to treat these wastes.

Related issues to implement this idea

1-Establish specialized institutes teaching disposal and recycling of wastes.

2- Prepare qualified cadres to treat wastes.

3- Provide wastes treatment machines and equipments

4- Development, treatment, disposal and recycling methods required.

The core strategic objectives of wastes management have a close relation with the trade policy, further more it leads to the basic laws of the trade operation in general. To implement this idea we should consider the following:-

- Study the environment.

-Markets development to produce products of less waste.

-Studying the Product

Produce products of less waste and recycle these wastes, use them or disposal of useless wastes.

Figure 1 simply clarifies the general organizational structure of the material economy.

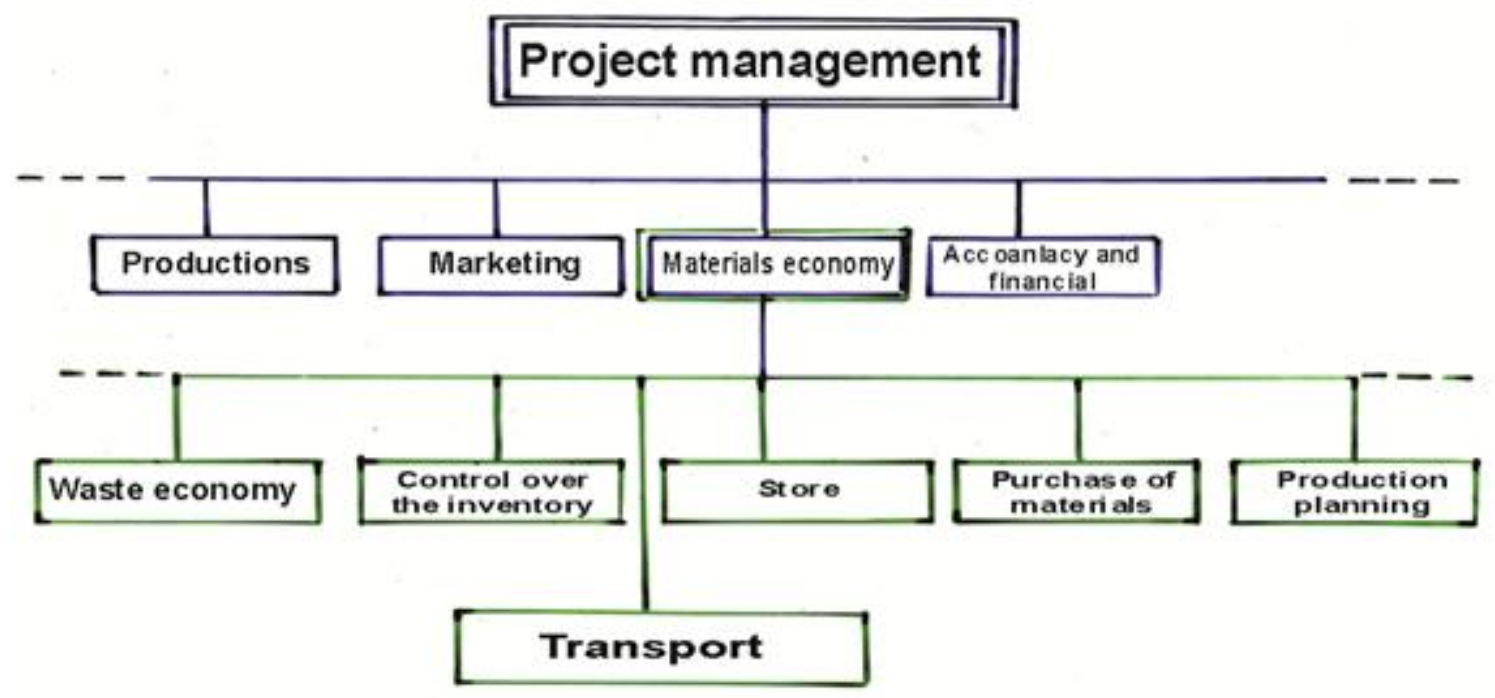

A simplified clarifies the organizational

structure of material economy

Figure Y

Figure 1; simplified clarifies the organizational structure of material economy 
-Define strength or weakness points

Train cadres, wastes management, optimal production and development methods.

-Development strategy

Develop a strategy to manage wastes, produce products with less wastes and recycling methods.

-Aimed objectives

- Developing production methods

- Transport and store and treatment

- Recycling of wastes

- Use of recycled waste

These objects are totally depending on available outcomes and closely related to the general economical objectives. The producers' profits are in line with the expenses of wastes treatments.

-Process of wastes management

Applicable laws play an impartment role in the process of wastes management and outline the general frame for the producers to deal with the wastes. This process includes recognizing, collecting, containing, classifying, transporting, storing, reuse of wastes, allocating places for wastes collection and developing investment projects.

Figure 2 shows a simplified model for the cycle of the secondary raw materials.

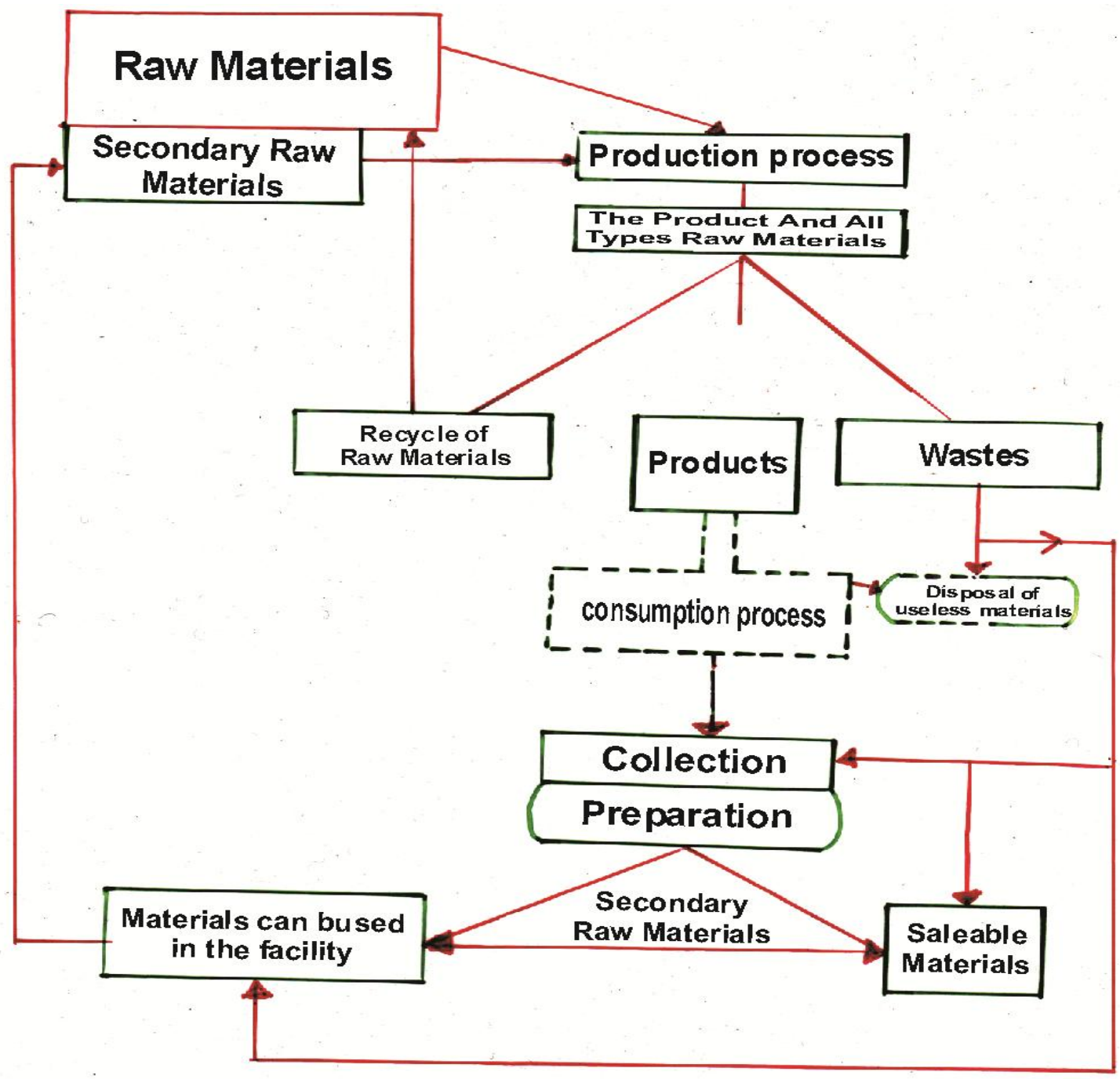

Figure one

\section{A Simplified Model for the Cycle of Secondary Raw Materials}

Figure 2; simplified model for the cycle of the secondary raw materials 
-The role of wastes management responsibilities in the management of materials

Organizing the process of wastes management plays an important role in selecting and transporting raw materials to the production facility and in maintaining the environment.

We have to notice that the production lines are not always alike in functions, so we should consider this process in order to organize work.

The management of materials develops a common relation with wastes management to produce a general frame work for the duties which are beyond familiar duties of purchase, store and transport operations, such as:-

-Organize and arrange quality as per the requirements

-Sort various types of wastes

- Test the materials

-Disposal and recycle of wastes at site or at treatment facilities

The special plans to deal with the above cited points and in accordance with state objectives should be conducted according to the available potentials, in addition to the recognition of applicable regulations, cost, changes and visibility studies.

The particle points related to the management of material also can be applied to the management of human resources that are related to planning and development of staff skills. Paying much attention to wastes management means a study of investment fields, organize special equipments related to wastes treatment, transport and loading. Storage facilities are considered as a priority in investment.

The main common posed questions are how to select the most suitable system among other systems alike as well as use durations and expansion capacities.

-The main factor in systemized reduction of wastes

The simplest requirements to reduce the quantity of wastes are the ability to control production capacity and partial objectives of the product. So reducing the quantity of wastes should take the whole system of the facility into consideration as well as the production strategy:

- Type and selection of the product

-labor plans and its use in required production.

- pay attention to wastes treatment

-Reduce wastes during the production process

- Select raw materials

_ Preparing wastes management system

- Wastes control and recycling process

- Create data base to recycle wastes.

Developing a model for important wastes previously prepared and establishing suitable systems in due time are considered a priority by the producers to insure quality assurance.

Figure 3 shows a sample of the process of recycling of the glass bottle to produce raw materials..
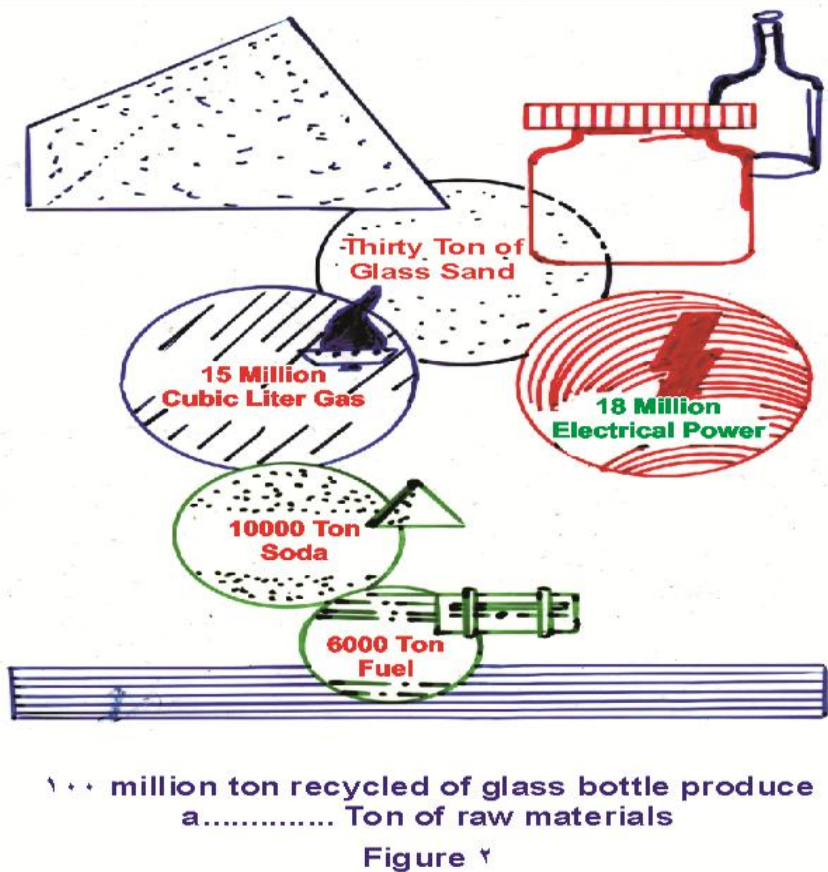

Figure 3; sample of the process of recycling of the glass bottle. 
-Environment protection is the responsibility of all

Currently, most of bodies that provide support to keep the environment clean can be listed, such as those who conducted through special studies using recycled materials which reduce production wastes improves living standard and reduce pollution levels.

Figure 4 shows the junks resulted from secondary raw materials that may be used to produce electrical refrigerator, iron bars and tractors.

\section{Junk resulted from secondary Raw Materials}

\begin{tabular}{|c|c|c|}
\hline & New Junk & \\
\hline Old junk & $\begin{array}{l}\text { Remainsand waster } \\
\text { out of mining and mineral }\end{array}$ & Collected junk \\
\hline
\end{tabular}

From people

\section{Consumption excluded fixed properties} ind ustries
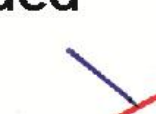

The industries of

pleriay east germany needs Y-o million ton per year to produce million of sjunk
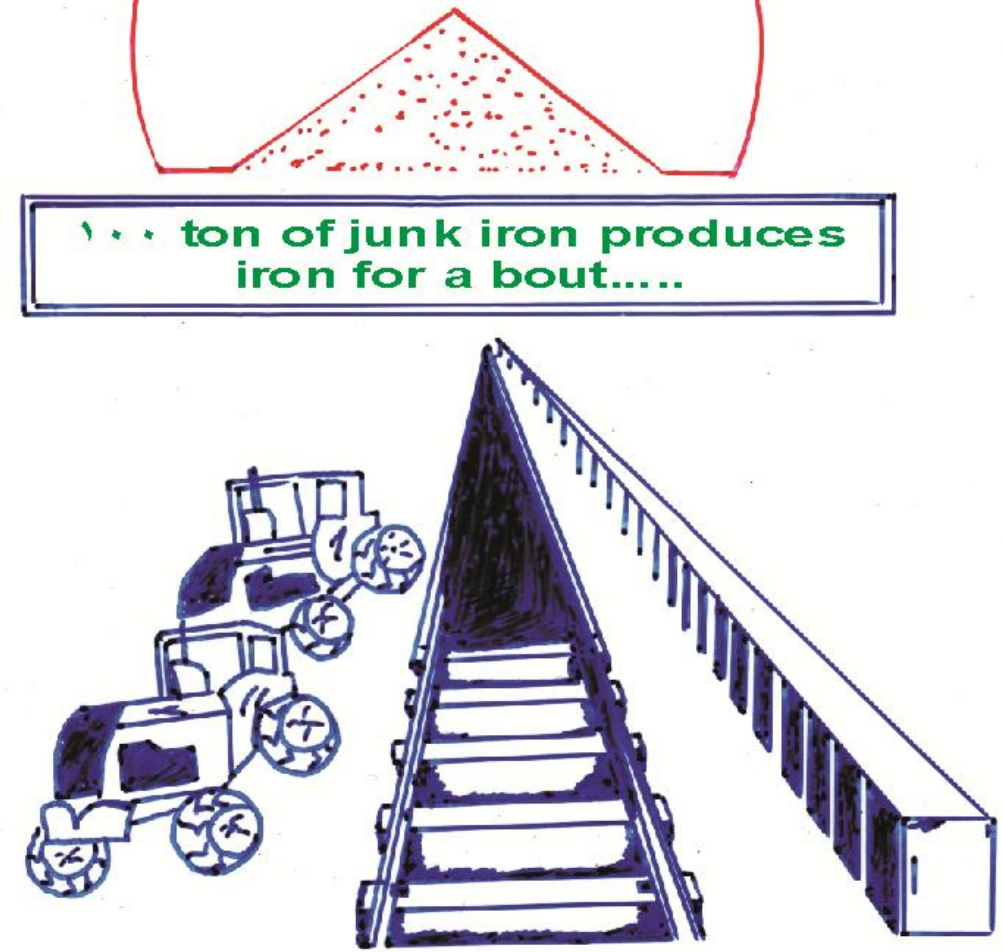

\section{Electrical refrigerator and iron bars and tractor and framing tractor}

Figure No . 1

Figure 4; junks resulted from secondary raw materials. 


\section{CONCLUSION}

Some of the tasks facing those who are concerned with environment across the world are the subject of looking for new raw materials which are easily disposed. The duties of producers are the disposal of wastes by a number of laws and regulations which can be a frame work for this subject. The optimal method to expand use of alternative raw materials is based on recycled materials, so importing important raw materials will be directed to another fields.

The problems that facing the production sector in Iraq is not getting ride of wastes as technical part of the production.

\section{REFERENCES}

1 blom, F. Abfallbeseitigung / Entsorgung, Beschaffung aktull 9188

2 Busch, h. p. , Einfuhrung in das Material management . Gabler Studientexte Wiesbaden 1986

3 ltartmanu, horst, material wivtschoft Organi sation, Planung Durch fuhrung Kontrolle, Taylorix Fachverlag . Stuttgails 1988

4 kummer, Kebastion, Grundzuge der Beschaftung Production und logistik person Stadium 2006

5 Merjan, Mujbil R . Logistik management Haus der arabischen, Babylon 2011

( arab. )

6 Plontek, Jochem Baugeine dvs logistik management Bremen 2009

7 Schulte, Ghristof, Logistik Wege Zur Optimierung der supply Ghain Vahlen 5 Awtlage Munchen , . .1 2009 